\title{
Effect of Centrifugal Casting on Microstructures and Properties of
} Hypereutectic Al-18wt.\%Si Alloy

\author{
Zhao $\mathrm{CHEN}^{1, \mathrm{a}}$, Yong $\mathrm{SU}^{2, \mathrm{~b}}$, and Sheng-Wei GONG ${ }^{3, \mathrm{c}}$ \\ School of Material Science and Engineering, Hefei University of Technology, Hefei 230009, China \\ aemail address: chenzhao0807@163.com \\ bemail address: suyong1963@126.com \\ cemail address: gongshengwei1994@163.com
}

Key words: Centrifugal casting; Al-18wt.\%Si Alloy; Primary Si; In-situ composites.

Abstract. Apply the centrifugal casting process to the preparation of hypereutectic Al-18\% Si alloy cylinder liners. In-situ gradient composites of Al-18wt.\%Si Alloy, which possess the microstructures of accumulated primary Si from outer layer to inner layer, have been acquired by changing the rotation rate of centrifugal casting. The distribution of primary $\mathrm{Si}$, the microstructure and hardness of the material were investigated. It was found that with the increase of centrifugal rotation rate, the primary $\mathrm{Si}$ of the outer layer is gradually shifted to the inner layer. And the rate is greater, the primary Si refinement effect is better. Meanwhile, the hardness of the material increased with the increase of the number of the primary $\mathrm{Si}$.

\section{Introduction}

Hypereutectic Al-Si alloy is an excellent wear-resistant materials, excellent casting properties, low coefficient of thermal expansion. Preparation of hypereutectic Al-Si alloy cylinder, compared with cast iron cylinder liners, a significant decline in weight, high thermal conductivity, improve engine efficiency, in addition to aluminum engine block due to the popularity of applications, high power operation, coefficient of thermal expansion of aluminum cylinder body and traditional cast iron cylinder liner vary widely, can cause distortion of the cylinder liner deformation, however, the use of high silicon aluminum alloy cylinder liner helps to improve engine life ${ }^{[1]}$. Centrifugal casting method of preparing Al-Si alloy cylinder liner has merit of the simple production process and high efficiency. Under centrifugal casting technology, small density primary phase segregates the interior part of the cast, so that it can greatly improve the wear resistance of the inside of the cylinder liner. Due to similar density of $\mathrm{Al}$ and $\mathrm{Si}\left(\mathrm{Al}: \rho=2.7 \mathrm{~g} / \mathrm{cm}^{3}, \mathrm{Si}: \rho=2.33 \mathrm{~g} / \mathrm{cm}^{3}\right)$, the centrifugal rotation rate control is particularly important, the appropriate centrifugal rotation can improve segregation of primary silicon in the interior part of the cast, but also can avoid crack, segregation and other defects on the casting ${ }^{[2]}$. By changing the rotational rate of the centrifugal casting, study the segregation case of primary silicon of $\mathrm{Al}-18 \% \mathrm{Si}$ alloy at different acceleration field, material microstructure and hardness.

\section{Experimental method}

\section{Experimental materials}

Using ZL109 alloy and industrial pure silicon as raw materials, the refining agent is C2Cl6, the modifier adopts Cu-P14 and Al-RE10 intermediate alloy, melting into Al-18wt.\%Si alloy in the Crucible resistance furnace. 
Tab.1 Composition of Al-18Si alloy (wt.\%)

\begin{tabular}{ccccccccc}
\hline $\mathrm{Si}$ & $\mathrm{Fe}$ & $\mathrm{Cu}$ & $\mathrm{Mn}$ & $\mathrm{Mg}$ & $\mathrm{Cr}$ & $\mathrm{Ni}$ & $\mathrm{Ti}$ & $\mathrm{Al}$ \\
\hline 18.076 & 0.249 & 4.619 & 0.04 & 0.185 & 0.152 & 4.172 & 0.019 & the remaining \\
\hline
\end{tabular}

\section{Experimental process}

Horizontal centrifuge is used in this experiment. For the three tests, of which the centrifugal rotation rates respectively adopt $1300 \mathrm{rpm}, 1100 \mathrm{rpm}$ and $1600 \mathrm{rpm}$, in addition to the different rotation rates, the same processes are as follows, before casting, metal mold will be preheated to $250^{\circ} \mathrm{C}$. When the alloy begins to melt, the surface is covered with a layer of covering agent, and then the temperature is increased to a refining temperature. Furnace temperature to be stabilized, add $\mathrm{C} 2 \mathrm{Cl} 6$ refining and let stand for 10 minutes, Slag with a skimming spoon, then quickly warmed to metamorphic temperature $\left(800 \sim 820^{\circ} \mathrm{C}\right)$, until the temperature stabilizes, adding P-RE compound modifier. After stirring fully, the solution surface a layer of coating agent to prevent oxidation of the alloy, heat for 30 minutes, began to cool. After the temperature dropped to refining, refining once again ${ }^{[3]}$. Standing, and then the temperature was raised to $800^{\circ} \mathrm{C}$, poured into a metal mold centrifugal casting mold, using three different centrifugal rotation rate to complete centrifugal casting. Obtained castings by centrifugal casting as a cylindrical part, has a diameter of $90 \mathrm{~mm}$, a wall thickness of $10 \mathrm{~mm}$, a height of $400 \mathrm{~mm}$.

In the middle of casting, intercept a sample height of $20 \mathrm{~mm}$ ring, then intercept on this sample width of $20 \mathrm{~mm}$ square samples. Grinding and polishing the circular cross section of the sample in the radial direction, then etching it with aqueous solution of HF of a volume fraction of $0.5 \%$ for 20s. On the sample after etching, from the outer wall to the inner wall, in turn select three different fields of view, observe its microstructure under metallurgical microscope.

\section{Experimental results and analysis}

\section{Metallographic structure analysis}

Figure 1 shows the microstructure of castings in the radial cross-section, in which Fig. a, d, g is the outer layer of the cast microstructure, Fig. b, e, h is the middle layer of the cast microstructure, and Fig. c, f, i is the inner layer of the cast microstructure. When the rotational rate is 1100rpm, casting organizations do not exist obvious stratification, which is composed of the white dendritic $\alpha$ (Al), flocculent eutectic $(\alpha+\mathrm{Si})$ and bulk primary crystal silicon; When the rotational rate is 1300rpm, the outer layer is of the presence of $\alpha(\mathrm{Al})$ matrix and a large number of eutectic silicon and a small amount of primary silicon, the primary silicon has begun to significantly shifted the inner layer, the middle layer aggregates a portion of primary silicon, the inner layer of primary silicon is more, and the majority of the angular block; When the rotational rate is 1600rpm, the stratification is very clear. The outer layer is almost invisible to the primary silicon, which is composed of a large number of flocculent eutectic silicon and $\alpha(\mathrm{Al})$ matrix. The middle layer has a small part of the primary silicon gathered together. In the inner layer, a large number of bulk primary silicon is enriched, but the sizes and the edges of the primary silicon are smaller and less than that of the primary silicon when the rotational rate is $1300 \mathrm{rpm}$.

In view of this, with increasing speed, primary silicon gradually shifted to the inner layer. And the faster rate, the more intense exercise, the collision with each other leads to that the massive primary silicon was fractured. It helps refine the primary silicon. 


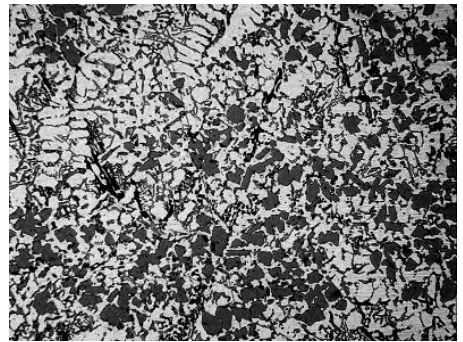

(a)

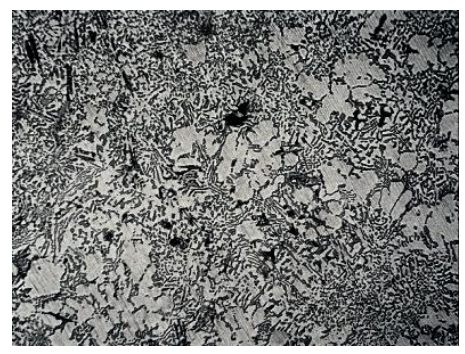

(d)

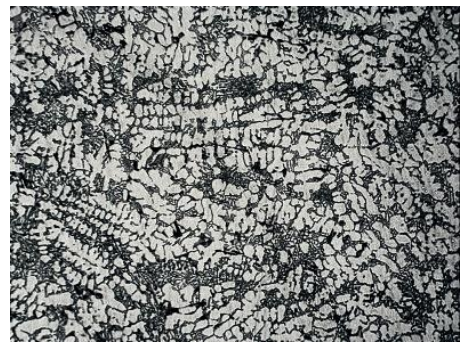

$(\mathrm{g})$

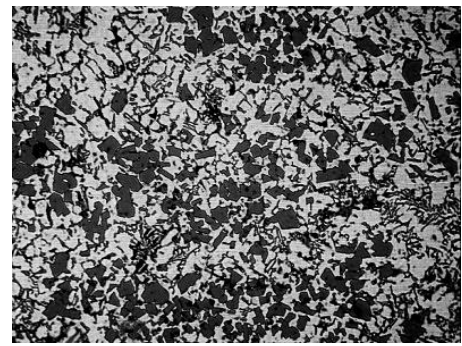

(b)

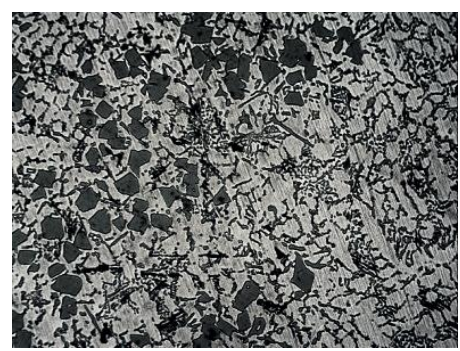

(e)

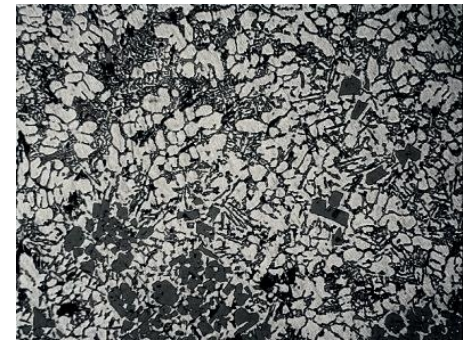

(h)

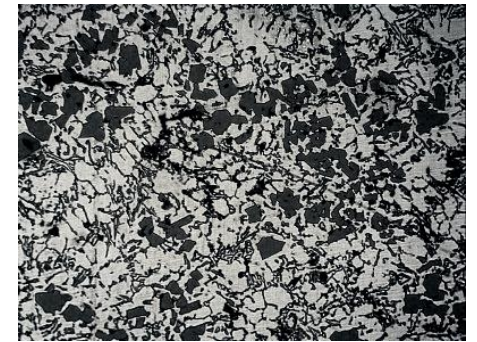

(c)

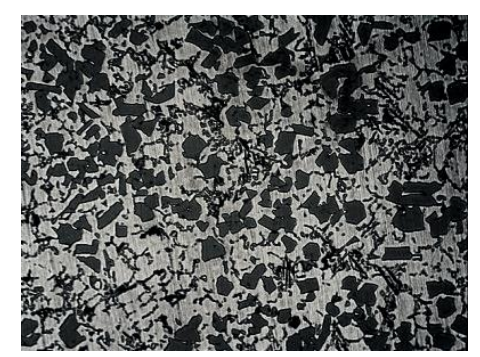

(f)

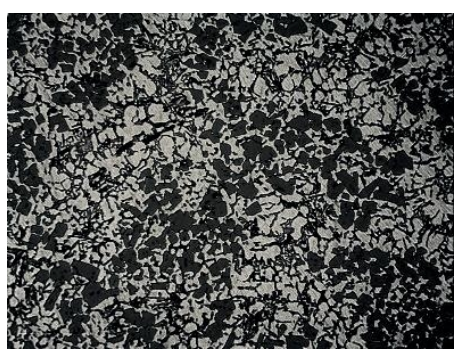

(i)

Fig.1 Microstructure of Al-18wt.\%Si alloy $(\times 100)$

(a),(b),(c): 1100r/min; (d),(e),(f): 1300r/min; (g),(h),(i): 1600 r/min; (a),(d),(g): Outer layer; (b),(e),(h): Middle layer; (c),(f),(i): Inner layer.

\section{Hardness testing of casting samples in different locations}

Using HV-1000 type micro Vickers hardness tester, were measured on the micro-hardness of the alpha (AL) matrix and primary crystal Si, loading alpha phase is $10 \mathrm{~g}$, loading the primary silicon is $50 \mathrm{~g}$, and their loading times are $15 \mathrm{~s}$, the measured micro-hardness of alpha phase is $83.0 \mathrm{HV}$, and the micro-hardness of primary $\mathrm{Si}$ is $887.5 \mathrm{HV}$. It can be known that the primary silicon as a hard phase, the higher the content, the greater the hardness of materials.

Using HB-3000B type Brinell hardness tester, with a diameter of $5.0 \mathrm{~mm}$ steel ball head and the load is $250 \mathrm{KG}$, the loading time is $30 \mathrm{~s}$. On the sample of radial direction from outside to inside in turn select the distance from the outermost 2.0, 5.0 and $8.0 \mathrm{~mm}$ three different locations, each region along the circumferential direction were tested three points, and then take the average. Meanwhile, T6 heat-treatment for casting, and the heat-treatment process is: solid solution temperature of $515 \pm 5^{\circ} \mathrm{C}$, solution time of $7 \mathrm{~h}$, artificial aging temperature of $185 \pm 5^{\circ} \mathrm{C}$, aging time of $11 \mathrm{~h}^{[4]}$. Repeat the above work, and test the hardness of castings after heat-treatment. 
Tab.2 Hardness of casting samples in different locations

\begin{tabular}{|l|l|l|l|l|l|l|}
\hline $\begin{array}{l}\text { rade } \\
\text { Position }\end{array}$ & $\begin{array}{l}\text { 1100rpm\# } \\
\text { Cast }\end{array}$ & $\begin{array}{l}\text { 1100rpm\# } \\
\text { Heat-treatment }\end{array}$ & $\begin{array}{l}\text { 1300rpm\# } \\
\text { Cast }\end{array}$ & $\begin{array}{l}\text { 1300rpm\# } \\
\text { Heat-treatment }\end{array}$ & $\begin{array}{l}\text { 1600rpm\# } \\
\text { Cast }\end{array}$ & $\begin{array}{l}\text { 1600rpm\# } \\
\text { Heat-treatment }\end{array}$ \\
\hline $\begin{array}{l}\text { Outer } \\
\text { layer }\end{array}$ & 106.7 & 113.7 & 98.0 & 102.7 & 96.1 & 101.1 \\
\hline $\begin{array}{l}\text { Middle } \\
\text { layer }\end{array}$ & 105.4 & 110.7 & 103.9 & 108.2 & 101.2 & 105.3 \\
\hline $\begin{array}{l}\text { Inner } \\
\text { layer }\end{array}$ & 104.0 & 110.0 & 114.3 & 118.0 & 118.3 & 121.3 \\
\hline
\end{tabular}

When the rotating speed is 1100rpm, it have no hierarchical difference in castings hardness; when the rotating speed is $1300 \mathrm{rpm}$ and $1600 \mathrm{rpm}$, middle layer and inner layer hardness is significantly higher than the outer layer and the inner layer hardness maximum; Consistent with the results of metallographic analysis, the primary silicon as a hard phase, the level of its content determines hardness of the material, when the rotational speed is $1100 \mathrm{rpm}$, the primary silicon without segregation phenomenon, the primary silicon present segregation at speed of 1300rpm and 1600rpm, gathered from the outer to the middle layer and inner layer, the inner primary silicon content is higher, thus, its hardness is larger; When the rotating speed is $1600 \mathrm{rpm}$, the inner layer hardness of casting reach to maximum, as $118.3 \mathrm{HBS}$.

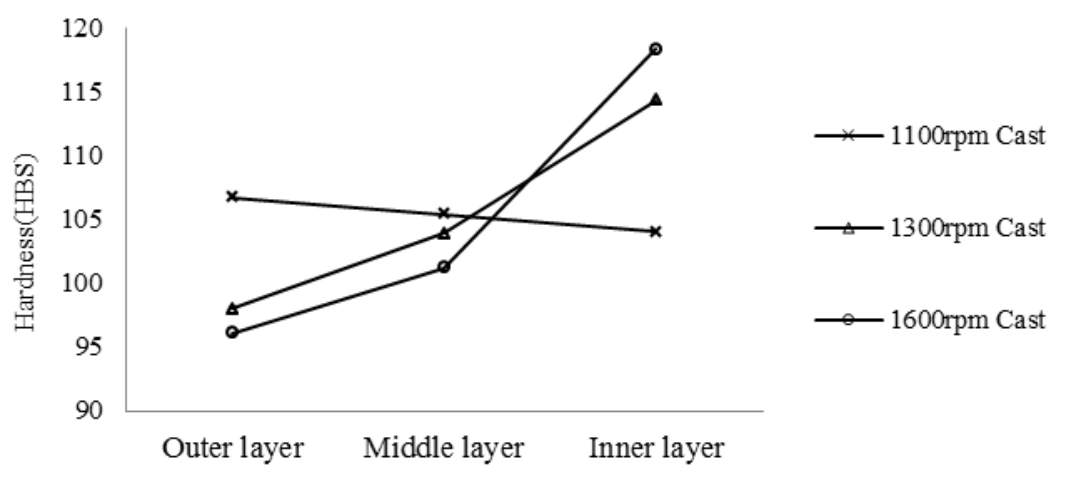

Fig.2 Hardness of castings

In addition, the micro-hardness of $\alpha$ phase in the heat-treatment state was 95.9HV, which was significantly increased compared with the as cast state. This shows that the solid solution strengthening of the matrix was obtained after heat-treatment. According to the composition of the material, mainly due to the solubility of $\mathrm{Cu}$ under heating conditions significantly increased, namely to the second phase $\mathrm{CuAl}_{2}$ dissolve into the matrix. After quenching can obtain single

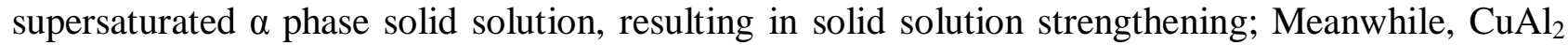
precipitated from the matrix in the aging process. Due to the small size, high dispersion, the ability to not easy to distort, also causing lattice distortion in the matrix to form the stress field, which has a clear blocking effect on the movement of the dislocation, thus increasing the plastic deformation resistance of the alloy to improve the strength and hardness ${ }^{[5] \sim[6]}$. This is consistent with the increase in hardness after heat treatment of castings. When the centrifugal rate reaches 1600rpm, the hardness of the cylinder liner's inner layer can reach 121.3HBS after heat-treatment by T6.

\section{Conclusion}

(1) With the increase of centrifugal rotation rate, the primary Si of the outer layer is gradually shifted to the inner layer. When the rate reaches $1600 \mathrm{rpm}$, the inner layer of the casting is formed as a primary silicon enrichment layer. And the faster rate, the more intense exercise, 
the collision with each other leads to that the massive primary silicon was fractured. It helps refine the primary silicon;

(2) The hardness of Al-18\% Si alloy composites is determined by the content of primary silicon. When the primary silicon content is in a gradient distribution, the hardness of the material also shows a gradient distribution;

(3) After heat-treatment by T6, the casting hardness will increase slightly. Mainly due to the solid solution strengthening of the matrix is obtained after heat-treatment. When the final centrifugal rotation rate reaches $1600 \mathrm{rpm}$, the hardness of the cylinder liner's inner layer can reach 121.3HBS after heat-treatment by T6.

\section{Acknowledgements}

This research is completed under the guidance of Professor Su. Here, thanks very much for his help.

\section{References}

[1] LAI Hua-qing, FAN Hong-xun, XU Xiang. Study and Application of Hypereutectic Al-Si Alloys[J]. Automobile Technology \& Material, 2001 (10): 21-24.

[2] Wang Qudong, Ding Wen-jiang, Jin Jun-ze. In-situ Surface Composites Fabricated by Centrifugally Casting Hypereutectic Al-Si Alloy[J]. ACTA MATERIAE COMPOSITAE SINICA, 1998, 15(3):7-13.

[3] Criado A J, Martinez J A, Calabres R. Growth of eutectic silicon from primary silicon crystals in aluminum-silicon alloys[J]. Scripta Materialia, 1997, 36(1): 47-54.

[4] Sun Yu, Chen Jin, Sun Guo-xiong. Evolution of Si Phase in Al-Si Alloy and Its Effect on Mechanical Properties[J]. Special Casting \& Nonferrous Alloys, 2006(6): 01-03.

[5] LI Run-xia, LI Rong-de, ZHAO Yu-hua. Effect of Heat-treatment on Eutectic Silicon Morphology and Mechanical Property of Al-Si-Cu-Mg Cast Alloys[J]. Trans. Nonferrous Met. Soc. China, 2004, 14(3): 496- 500.

[6] Wolverton C, Ozolins V. Entropically Favored Ordering: the Metallurgy of $\mathrm{Al}_{2} \mathrm{Cu}$ Revisited[J]. PHYS REV LETT, 2001, 24(86): 5518-5521. 